\title{
Closed System Evaporative Fractionation as a tool to Reservoir Alteration
}

\author{
Swapan Kumar Bhattacharya ${ }^{1}$, Syazaila Wasli ${ }^{1}$. \\ ${ }^{I}$ (Department of Petroleum Geoscience, Universiti Teknologi Petronas, Bandar Sei Iskandar, 31750 Tronoh, \\ Perak Darul Ridzuan, Malaysia).
}

\begin{abstract}
Evaporative fractionation of petroleum by gas injection over oil was established by Thompson. In this process he could fractionate reservoir petroleum to paraffin rich condensate in the shallow reservoir and aromatic rich residual oil in the original reservoir. In the present work attempt has been made to test fractionation by heating crude oil in a closed system to build up adequate vapour pressure necessary for fractionation in the vapour phase condition. The technique has been tested using Sabah oil of East Malaysia and Dulang oil of Peninsular Malaysia. Results of present experiment indicate aromatic rich condensate in the shallower reservoir and paraffin rich residual oil in the original reservoir. It is therefore concluded that evaporative fractionation can alter the nature of reservoir oil to paraffin rich or aromatic rich depending on the process of fractionation.
\end{abstract}

Keywords: Aromaticity, Crude Oil, Evaporative fractionation, Paraffinicity, Reservoir alteration

\section{Introduction}

Vapour phase fractionation of crude oil, also known as evaporative fractionation, generates different types condensates (liquid generated by condensation of the vapour) compared to the residual oil. Thompson [1] first established this technique to explain paraffin rich condensate in the shallower reservoirs compared to aromatic rich fractionated residual oil in the deeper reservoirs. Earlier, Silverman [2] named it as separationmigration process as a result of chemical differentiation. However, Thompson experimentally showed results of paraffin rich fractionated condensates by injecting methane over the oil column. He proposed this mechanism particularly for gas-condensate system whereby initial oil is rich in dissolved gas and fractionation happened with movement of gas cap gas.

Scope of further research remained to test fractionation under different vapour conditions. In the present work fractionation is carried out by heating oil in a closed system to build sufficient pressure over the oil column and the vapour in this condition is released to fractionate the crude oil.

\section{Experiment}

Experiments are carried out using modified Parr High Pressure Reactor. Sample oils from Sabah Basin of Eastern Malaysia and Dulang Field of Peninsular Malaysia are used for this experiment. Parr Reactor has got two separate valves for collecting liquid and vapour samples. A condenser is connected to the vapour exit to collect condensate samples. About $350 \mathrm{ml}$ of oil sample is put into the glass cylinder of the Parr Reactor. The oil sample is then heated gradually to higher temperatures to a maximum of $250^{\circ} \mathrm{C}$ temperature. The heating of oil sample is repeated until vapour samples were collected at 20, 40,60 and 80 psi pressures. The instrument has got facility to increase pressure in the closed system. This enabled to collect samples at different pressures at a particular temperature. The first set of four samples is collected at $100^{\circ} \mathrm{C}$. Sets of four samples in four different pressures are then collected at $150^{\circ} \mathrm{C}, 200^{\circ} \mathrm{C}$ and $250^{\circ} \mathrm{C}$ temperatures. The samples of condensed vapour and crude oil are analyzed for paraffinicity and aromaticity.

\section{Chemistry Of Closed System Evaporative Fractionation}

It is known that paraffin have higher vapour pressure compared to aromatics of same carbon number [3]. This is why oil if put under atmospheric condition will have vapours enriched with paraffin. As done by Thompson, the vapour is removed gradually so that the residual oil becomes aromatic rich.

Instead of removing the vapour, if we heat the system and allow vapours to build up high pressure over the oil column then following Le- Chatelier principle [4] the vapour molecules will try to move to liquid phase to nullify the effect of pressure. The paraffin being more mobile, move faster than aromatics to liquids but when the liquid temperature is higher than the boiling point of the paraffin, the vapour molecules polymerize and condense to form large molecules and return back to liquid to build high wax in oil.

The partial vapour pressure $\left(\mathrm{P}_{\mathrm{a}}\right)$ of any substance ' $\mathrm{A}$ ' in a mixture at a particular temperature is given by Raoult's Law [5] as,

$$
\mathrm{P}_{\mathrm{a}}=\mathrm{P}_{\mathrm{a}}^{\mathrm{o}} \cdot \mathrm{x}_{\mathrm{a}}
$$


Where, $\mathrm{P}_{\mathrm{a}}{ }^{\mathrm{o}}$ is the vapour pressure of the pure component at the same temperature and pressure and $\mathrm{x}_{\mathrm{a}}$ is the mole-fraction of the component in the liquid.

Dalton's Law [6] states that $\mathrm{P}_{\mathrm{a}}$ is the product of total pressure and mole-fraction of the vapour ,

$$
\mathrm{P}_{\mathrm{a}}=\mathrm{P}_{\text {Tot. }} \mathrm{y}_{\mathrm{a}} \text {----- (Eq.2) }
$$

Where, ' $\mathrm{y}_{\mathrm{a}}$ ' is the mole fraction of ' $\mathrm{A}$ ' in the vapour. Combining (Eq.1) and (Eq.2) we get,

$$
\begin{gathered}
\mathrm{P}_{\mathrm{a}}{ }^{\circ} \cdot \mathrm{x}_{\mathrm{a}}=\mathrm{P}_{\text {Tot }} \mathrm{y}_{\mathrm{a}} \text {--.- (Eq.3) } \\
\text { Or, } \mathrm{x}_{\mathrm{a}} / \mathrm{y}_{\mathrm{a}}=\mathrm{P}_{\text {Tot }} / \mathrm{P}_{\mathrm{a}}{ }^{\mathrm{o}} \text {---- (Eq.3) }
\end{gathered}
$$

This suggests, as the total pressure $\left(\mathrm{P}_{\text {Tot }}\right)$ is increased at a specific temperature, the mole-fraction of ' $\mathrm{A}$ ' in the liquid is also increased suggesting moles of ' $\mathrm{A}$ ' from the vapour will transfer to liquid. Paraffin being compounds of high vapour pressure usually evaporate first and as the aromatics vaporise creating higher pressure in a closed system, the paraffin from the vapour is condensed to liquid making liquid paraffin rich. Following equation (Eq.3) we can write equation (Eq.4) for compound ' $b$ ' as -

$$
\mathrm{x}_{\mathrm{b}} / \mathrm{y}_{\mathrm{b}}=\mathrm{P}_{\mathrm{Tot}} / \mathrm{P}_{\mathrm{b}}{ }^{\mathrm{o}} \text {----- (Eq.4) }
$$

Where, $x_{b}$ is the mole fraction of ' $b$ ' in the liquid, $y_{b}$ is the mole fraction of ' $b$ ' in the vapour and $\mathrm{P}_{b}{ }^{\circ}$ is the vapour pressure of pure compound 'b'. Dividing (Eq.3) by (Eq.4) we get,

$$
(\mathrm{xa} / \mathrm{xb}) .(\mathrm{yb} / \mathrm{ya})=\mathrm{P}_{\mathrm{b}}{ }^{0} / \mathrm{P}_{\mathrm{a}}{ }^{0}-\mathrm{-}^{-} \text {(Eq.5) }
$$

Paraffinicity and aromaticity are calculated using 'Thompson Parameters' as follows.

$$
\begin{aligned}
\text { Paraffinicity } & =\frac{\text { N-heptane }}{\text { Methyl cyclo-hexane }} \\
\text { Aromaticity } & =\frac{\text { Toluene }}{\text { N-heptane }}
\end{aligned}
$$

In (Eq.5) let ' $a$ ' is n-heptane and ' $b$ ' is methyl cyclo-hexane. Then, ratio of paraffinicity in the liquid to paraffinicity in the vapour at a particular temperature and pressure is equal to the ratio of vapour pressures of pure 'methyl cyclo-hexane' and pure ' $n$-heptane'. Thus we see in a mixture of n-heptane and methyl cyclohexane, paraffinicity in the vapour is high because vapour pressure of $n$-heptane is high. If we remove the vapour, the residual oil will be aromatic rich what Thompson has achieved. Instead, if we heat the system to generate more vapour pressure the system will no longer behave in the same manner because at high temperature and pressure individual compounds will suffer cracking, polymerization, condensation and aromatization reactions. At the same time according to Le-Chatelier principle, when temperature and pressure is increased, the system will adjust to nullify the effects of such change. High molecular paraffin waxes are known as heat sinks [7]. In the high pressure high temperature conditions, the system generates high molecular paraffin wax and send it to liquid phase. Zhang et al. [8] showed closed system pyrolysis of n-octadecane generates $\mathrm{C}_{18}{ }^{+}$ hydrocarbons during closed system pyrolysis. Thus it is possible to generate high paraffin liquid by closed system evaporative fractionation.

In this present experiment the results of residual liquid is being ignored because the samples of liquid remained in equilibrium with vapour and at higher temperature and pressure all the compounds of $n$-heptane, methyl-cyclohexane or toluene are gradually reduced. However, sample is also analyzed for left over oil at the end of the experiment.

\section{Results \& Discussions}

Paraffinicity and aromaticity for each of the vapour samples of Sabah oil and Dulang oil are shown in Table-1 and Table-2 respectively. Changes of paraffinicity and aromaticity with pressure at different temperatures are shown in Figs.1and 2. 

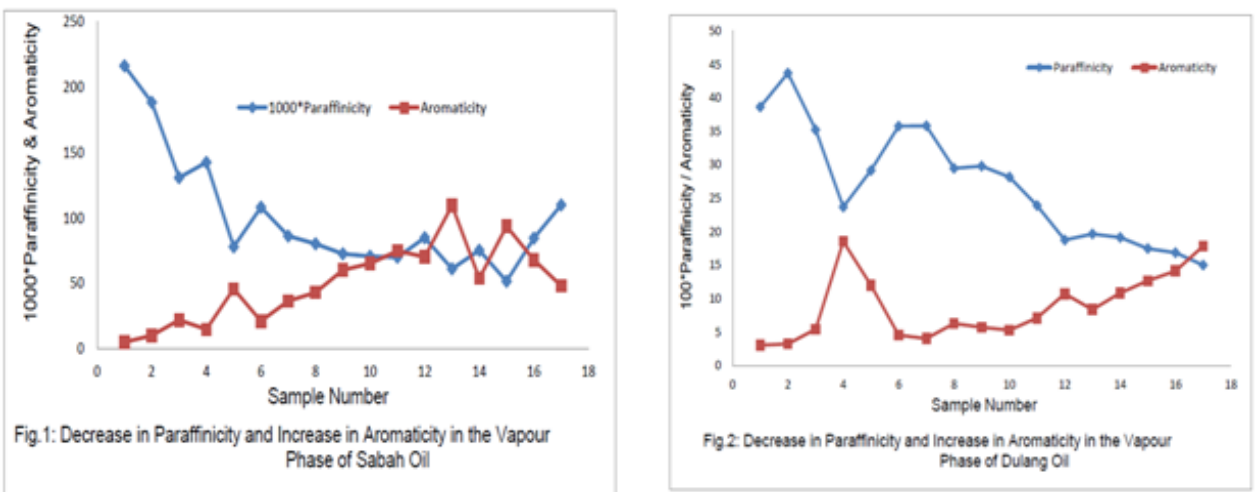

Results of both the oil samples suggest increase in aromaticity and decrease in paraffinicity in their corresponding vapours during closed system evaporative fractionation.Closed system evaporative fractionation works on the principle in which vapour is allowed to move out of the system only when desired extra pressure is generated as a result of which it is revealed that vapour is enriched with aromatics. Effects of pressure individually on the paraffins or aromatics have also been studied. Results confirm the decrease in Parafinicity in the vapour with pressure (Fig.3) and the increase in aromaticity with pressure (Fig.4).
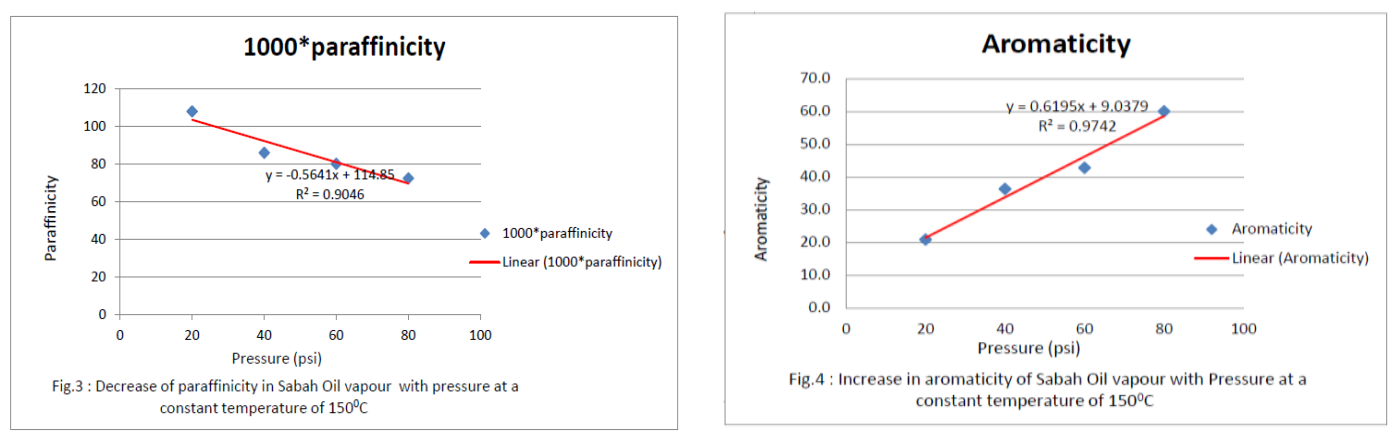

Results also corroborate earlier works of Yarborough [9] who only analysed aromaticity.

Effects of temperature however show exponential increase of aromaticity (Fig.5) and exponential decrease of paraffinicity (Fig.6) in the vapours.
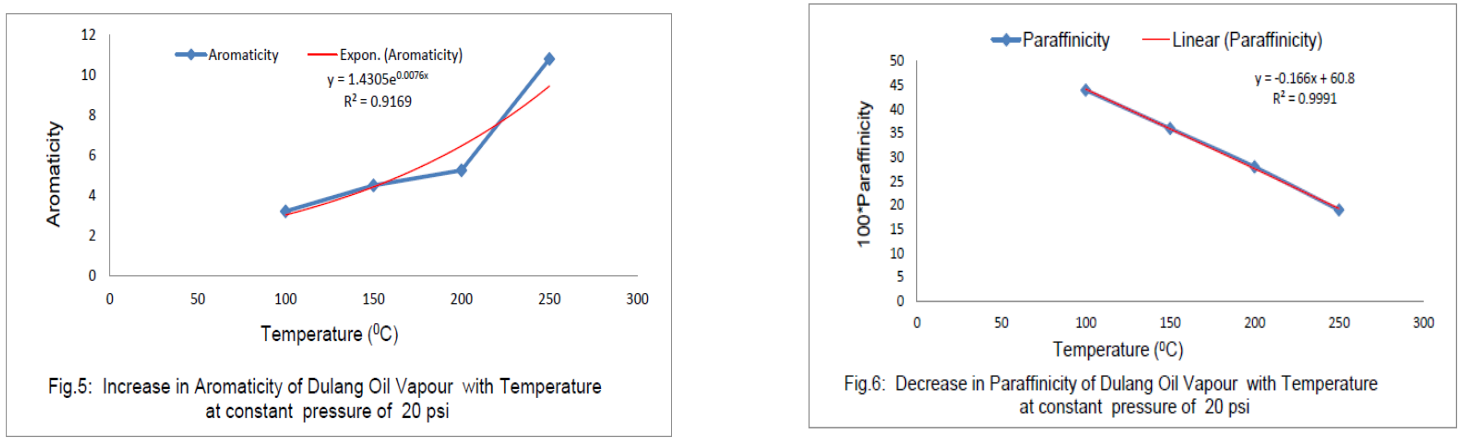

As the temperature is getting higher, the amount of $n$-heptane in vapour is reduced suggesting it has gone to liquid phase but at that high temperature it cannot exist as n-heptane in the liquid and therefore it is expected to have been converted to higher homologue as a result of which in the liquid phase also increased nheptane is not available. Higher homologues ultimately generate more wax in the residual oil. Results of the vapour phase samples thus represent the evaporative fractionation changes of petroleum. The residual oil sample of Dulang when cooled was available as solid wax suggesting residual oil was continuously getting enriched with paraffin wax. Sabah oil was not solidified because the initial Paraffinicity was nearly half of the Dulang oil. Although the studied pressure ranges are too low compared to the reservoir pressure but the trends suggest vapour gets depleted in paraffin with higher pressure.

\section{Conclusion}

Based on the results above it is concluded that evaporative fractionation also results by closed system heating which will generate paraffin rich oil at the deeper section and corresponding aromatic rich oil in the 
shallower reservoirs. Although the pressures in the above experiment are in no way comparable to the reservoir pressure, conclusion is drawn based on the theory (Eq.5) and the trend line (Fig.3) of the available results. Evaporative fractionation appears to be one of the major mechanisms of reservoir alterations of crude oils. Occurrence of high paraffin basement oil associated with relatively higher aromatic rich oil in shallower reservoirs may be considered as formed by reservoir alteration following such modified evaporative fractionation technique.

\section{Acknowledgement}

Authors acknowledge financial assistance of UTP and constant encouragement of the Pet.Geoscience department to carry out this research. Authors also acknowledge constant laboratory support of Chemistry department for use of high pressure reactor and centralized laboratory support of UTP for constant use of GCMS analysis of the samples.

\section{References:}

[1]. K. F. M. Thompson, Fractionated aromatic petroleum and the generation of gas condensates, Org. Geochem. 11(6), 1987, 573 590.

[2]. S. R. Silverman, Migration and segregation of oil and gas. In A. Young and G. E. Galley (eds.) AAPG Memoir 4. Fluids in subsurface environments, 1965, 53-65.

[3]. J.M. Hunt, Petroleum Geochemistry and Geology ( $2^{\text {nd }}$ Edition). W.H. Freeman and Co. New York, 433 (1996)

[4]. Gladstone, S. Text Book of Physical Chemistry. Macmillan and co. Limited. New York. $2^{\text {nd }}$ Edition, 1962.

[5]. Raoult F. M. (1982) http://en.wikipedia.org/wiki/Raoult's law

[6]. Wikipedia available at: http://en.wikipedia.org/wiki/Paraffin wax , (30.03.2013)

[7]. H. Zeng, A. Geng, Y. Xiong, L. Jinzhong and L. Jinping. ) Closed-system programmed-temperature pyrolysis on n-octadecane: Implications for the conversion of oil to gas. Geochemical Journal. 42, 2008, $403-412$.

[8]. L.Yarborough, Vapour-Liquid equilibrium data for multicomponent mixtures containing hydrocarbon and non-hydrocarbon components. J. Chem. Eng. Data. 17, 1972, 129-133.

Table-1:

\begin{tabular}{|c|c|c|c|c|c|c|c|}
\hline Samples & $\begin{array}{l}\text { Temp. } \\
\text { (deg.C) }\end{array}$ & Press. (psi) & n-heptane $\%$ & $\begin{array}{c}\text { Methyl } \\
\text { cyclo-hexane } \\
\%\end{array}$ & Toluene $\%$ & $\begin{array}{c}1000^{\circ} \\
\text { Paraffinicity }\end{array}$ & Aromaticity \\
\hline Original oil & $\begin{array}{l}\text { Room } \\
\text { Temp. }\end{array}$ & Atm.Press & 3.94 & 18.22 & 19.09 & 216 & 4.85 \\
\hline Condensate 1 & 100 & 20 & 3.26 & 17.31 & 32.15 & 188 & 9.86 \\
\hline Condensate 2 & 100 & 40 & 1.49 & 11.4 & 32.45 & 131 & 21.78 \\
\hline Condensate 3 & 100 & 60 & 2.43 & 17.07 & 35.62 & 142 & 14.66 \\
\hline Condensate 4 & 100 & 80 & 0.76 & 9.77 & 34.71 & 78 & 45.67 \\
\hline Condensate 5 & 150 & 20 & 1.52 & 14.07 & 31.75 & 108 & 20.89 \\
\hline Condensate 6 & 150 & 40 & 0.96 & 11.16 & 34.88 & 86 & 36.33 \\
\hline Condensate 7 & 150 & 60 & 0.81 & 10.11 & 34.66 & 80 & 42.79 \\
\hline Condensate 8 & 150 & 80 & 0.59 & 8.15 & 35.42 & 72 & 60.03 \\
\hline Condensate 9 & 200 & 20 & 0.55 & 7.8 & 35.78 & 71 & 65.05 \\
\hline Condensate 10 & 200 & 40 & 0.53 & 7.59 & 39.54 & 70 & 74.60 \\
\hline Condensate 11 & 200 & 60 & 0.55 & 6.49 & 38.54 & 85 & 70.07 \\
\hline Condensate 12 & 200 & 80 & 0.38 & 6.23 & 41.58 & 61 & 109.42 \\
\hline Condensate 13 & 250 & 20 & 0.77 & 10.25 & 41.3 & 75 & 53.64 \\
\hline Condensate 14 & 250 & 40 & 0.47 & 9.14 & 43.96 & 51 & 93.53 \\
\hline
\end{tabular}

Table-2:

\begin{tabular}{|c|c|c|c|c|c|c|c|}
\hline Samples & $\begin{array}{l}\text { Temp. } \\
\text { (deg.C) }\end{array}$ & Press. (psi) & n-heptane $\%$ & $\begin{array}{l}\text { Methyl cyclo- } \\
\text { hexane } \%\end{array}$ & Toluene \% & $100^{\circ}$ Parafinicity & Aromaticity \\
\hline Original oil & Room & Atm. & 6.02 & 15.59 & 18.14 & 39 & 3.01 \\
\hline Condensate 1 & 100 & 20 & 6.56 & 15.02 & 21.18 & 44 & 3.23 \\
\hline Condensate 2 & 100 & 40 & 4.06 & 11.53 & 21.98 & 35 & 5.41 \\
\hline Condensate 3 & 100 & 60 & 0.89 & 3.76 & 16.48 & 24 & 18.52 \\
\hline Condensate 4 & 100 & 80 & 1.69 & 5.8 & 20.25 & 29 & 11.98 \\
\hline Condensate 5 & 150 & 20 & 5.07 & 14.18 & 22.94 & 36 & 4.52 \\
\hline Condensate 6 & 150 & 40 & 5.71 & 15.95 & 22.94 & 36 & 4.02 \\
\hline Condensate 7 & 150 & 60 & 3.8 & 12.9 & 23.77 & 29 & 6.26 \\
\hline Condensate 8 & 150 & 80 & 4.24 & 14.24 & 24.18 & 30 & 5.7 \\
\hline Condensate 9 & 200 & 20 & 4.56 & 16.2 & 24.03 & 28 & 5.27 \\
\hline Condensate 10 & 200 & 40 & 3.42 & 14.32 & 24.27 & 24 & 7.1 \\
\hline Condensate 11 & 200 & 60 & 2.15 & 11.47 & 23.02 & 19 & 10.71 \\
\hline Condensate 12 & 200 & 80 & 2.94 & 14.97 & 24.53 & 20 & 8.34 \\
\hline Condensate 13 & 250 & 20 & 2.49 & 13.02 & 26.94 & 19 & 10.82 \\
\hline Condensate 14 & 250 & 40 & 2.11 & 12.09 & 26.7 & 17 & 12.65 \\
\hline Condensate 15 & 250 & 60 & 1.83 & 10.86 & 25.83 & 17 & 14.11 \\
\hline Condensate 16 & 250 & 80 & 1.52 & 10.13 & 27.09 & 15 & 17.82 \\
\hline
\end{tabular}


List of Tables:

Table-1: Paraffinicity and Aromaticity of the vapour samples of Sabah Oil in Malaysia

Table-2: Paraffinicity and Aromaticity of the vapour samples of Dulang Oil in Malaysia

\section{List of Figures}

Fig.1: Decrease in Paraffinicity and increase in Aromaticity in the vapour phase of Sabah oil.

Fig.2: Decrease in Paraffinicity and increase in Aromaticity in the vapour phase of Dulang oil.

Fig.3: Decrease in Paraffinicity in Sabah oil vapour with pressure at constant temperature of $150^{\circ} \mathrm{C}$

Fig.4: Increase in Aromaticity in Sabah oil vapour with pressure at constant temperature of $150^{\circ} \mathrm{C}$

Fig.5: Increase in Aromaticity of Dulang oil vapour with temperature at constant pressure of $20 \mathrm{psi}$

Fig.6: Decrease in Paraffinicity of Dulang oil vapour with temperature at constant pressure of 20psi 